\title{
Tradução
}

\section{Schopenhauer e a fisiologia francesa: (Cabanis e Bichat), de Paul Janet}

\author{
Caio Souto' (iD, lasmim Martins ${ }^{11}$ (D) \\ 'Instituto Federal do Amazonas,Presidente Figueiredo, AM, Brasil \\ " Universidade Federal do Rio de Janeiro, Rio de Janeiro, RJ, Brasil
}

\section{INTRODUÇÃO}

Schopenhauer escrevia, em 1852, a seu amigo Frauenstädt: “Há um certo V... que se permite tratar como superficiais os escritos imortais de Bichat e a partir desse juízo crê-se dispensado da leitura de Bichat e de Cabanis... Bichat não viveu mais que trinta anos e toda a Europa letrada honra seu nome e lê seus escritos... Sem dúvida, desde Bichat a fisiologia fez progressos, mas não de maneira a fazer esquecer Cabanis e Bichat... Por favor, não escreva nada sobre a fisiologia em relação com a psicologia sem ter se nutrido do sumo e do sangue de Cabanis e de Bichat".

Vemos por essas palavras que alta ideia Schopenhauer fazia dos dois médicos filósofos que ilustraram o começo de nosso século. Não foi apenas em uma carta, e de passagem, que Schopenhauer emitiu tal juízo: foi também em seus escritos filosóficos que ele, além de render honrarias a esses dois pensadores, ainda reconheceu expressamente a parte que Ihes cabia na formação de sua própria filosofia. Nos Esclarecimentos (mais interessantes, talvez, do que o próprio livro), que compõem o segundo volume de $O$ mundo como vontade e representação, eis como ele se exprime: "Há duas maneiras essencialmente diferentes de 
considerar a inteligência: uma subjetiva, partindo de dentro e tomando a consciência como algo dado;... Este método, do qual Locke é o criador, foi conduzido por Kant à mais alta perfeição. Mas há um outro método de observação inteiramente oposto a este; é o método objetivo, que parte de fora e que toma por objeto, não a experiência interna, mas os seres dados na experiência externa, e que busca qual relação a inteligência, nesses seres, pode ter com suas outras propriedades... Este é o método empírico, que aceita como dados o mundo exterior e os animais que nele estão contidos. Este método é zoológico, anatômico, fisiológico... Os seus primeiros fundamentos se devem aos zoólogos e aos fisiólogos, notadamente aos franceses. É preciso nomear, aqui, sobretudo Cabanis, cuja excelente obra sobre as Relações entre o físico e o moral no homem abriu a via [bahabrechend] nessa direção. Depois dele, é preciso nomear Bichat, cujo ponto de vista é ainda mais extenso. Não se deve esquecer também Gall, embora seu objetivo principal tenha sido esquecido".

Essa passagem característica nos ensina que, se Schopenhauer deveu a Kant e a Fichte toda a parte subjetiva de sua filosofia, é a Cabanis, a Bichat e em geral aos fisiólogos ingleses e franceses (ele cita com frequência Lamarck, Bell e Magendie), que ele deve a sua parte objetiva. Se o primeiro livro de sua obra vem de Kant, é permitido dizer que o segundo vem, em grande parte, de Cabanis e de Bichat. É interessante ver esse curioso retorno do prestígio da filosofia francesa do século XVIII na Alemanha, essa vingança do realismo fisiológico sobre o idealismo metafísico. Aliás, independentemente mesmo desse interesse, Cabanis e Bichat são por si mesmos pensadores eminentes bastante esquecidos, embora ao alcance de todos, e cujo valor se eleva hoje singularmente pelo encontro com o espírito de nosso tempo, e pelo próprio retorno das ideias que defendiam. 
Quando Cabanis escreveu suas primeiras notas sobre as Relações entre o físico e o moral, o Institut de France acabava de ser fundado. Uma classe nova (haviase renunciado à palavra academia) tinha sido estabelecida: a classe das ciências morais e políticas, que foi suprimida pelo primeiro cônsul depois de ter durado cinco anos, por ser composta por ditos ideólogos, e só foi restabelecida mais tarde, em 1832, por Guizot, sob a forma que mantém até hoje. Os principais desses ideólogos que tanto desagradaram ao General Bonaparte eram Destutt de Tracy e Cabanis: o primeiro, membro liberal do Conselho dos Quinhentos do Diretório; o outro, amigo de Mirabeau. Ambos dedicados à análise das sensações e das ideias, como era então chamada a filosofia, mas um servindo-se sobretudo do método subjetivo, o outro do método objetivo; um deles mais ideólogo, tendo ele mesmo inventado a palavra, o outro mais fisiólogo e médico; ambos alunos convictos de Condillac, mas trabalhando ao mesmo tempo para desenvolver e reformar seu pensamento. O primeiro, restituindo ao espírito humano, antes de Maine de Biran, um germe de atividade desconhecido por Condillac, para quem o eu seria inteiramente passivo; o segundo restabelecendo na estátua ${ }^{1}$ do mestre um elemento inato e espontâneo, sacrificado por este a uma exterioridade completamente mecânica. Destutt de Tracy mereceria, sem dúvida, um estudo à parte, mas que nos afastaria muito de nosso objeto: devemos nos limitar a Cabanis.

Cabanis é conhecido sobretudo na história da filosofia como representante do materialismo, e é preciso convir que ele teve a infelicidade de fornecer a essa doutrina uma de suas fórmulas mais desajeitadas e revoltantes. Foi ele que disse que o cérebro digere os pensamentos como o estômago digere os alimentos, e que opera, a rigor, a "secreção do pensamento" ${ }^{2}$. Foi também ele que disse que "a moral

\footnotetext{
${ }^{1}$ No Tratado das sensações, de 1754, Condillac lança mão da figura de uma estátua de mármore à qual irá acrescentando sentidos para exemplificar sua filosofia sensualista. [N.T.]

${ }^{2} \mathrm{C}$. Vogt teve a feliz ideia de ampliar essa expressão e apresentar o mesmo pensamento de uma forma ainda mais agradável à mente, dizendo que o cérebro secreta o pensamento como "os rins secretam a
} 
é apenas a física considerada sob certos pontos de vista particulares". Contudo, talvez não devêssemos exagerar o valor de certas expressões malsoantes. Não apenas podemos invocar sua Carta sobre as causas primeiras, escrita mais tarde na verdade, mas de um ponto de vista muito superior ao dos materialistas, mas também devemos lembrar que o próprio Cabanis, em sua obra mais famosa, protesta contra a intenção de ter escrito para promover uma certa filosofia particular: declara-se incompetente para tudo o que diz respeito às causas primeiras e pretende não se ter deslocado para além do ponto de vista da experiência; a verdade é que as expressões assinaladas acima não fazem parte integrante do essencial de sua obra, podendo ser suprimidas sem alterar o seu caráter. E, exceto por uma parte muito grande da influência talvez concedida ao físico, o que é bastante natural para um médico, a obra como um todo pode ser aproveitada e até aceita por todas as filosofias. Tentaremos mostrar que o fundo da filosofia de Cabanis, mesmo nas Relações entre o físico e o moral, é uma filosofia original e nova, e que ela deve ser considerada sobretudo como uma reforma da filosofia de Condillac. Destutt de Tracy já havia começado essa reforma, mas ele se limitou a um ponto; Cabanis escavou até os fundamentos do condillaquismo e mostrou que sob esses alicerces existem outros que Condillac não tinha percebido. Talvez essa crítica a Condillac não tenha sido notada o suficiente, pois na verdade está espalhada em diferentes partes do livro e não se encontra condensada como um todo em nenhum lugar. Tentemos reconstruir essa polêmica, sem nada acrescentar a ela, apenas modificando a ordem das ideias.

Cabanis, como todos os filósofos franceses do século XVIII, considera o empreendimento de Condillac como uma obra de gênio que deveria estabelecer a filosofia sobre fundamentos inabaláveis: “Foi, diz ele, um empreendimento digno da filosofia do século XVIII decompor o espírito humano e reduzir suas operações a um pequeno número de comandos elementares; foi um verdadeiro traço de 
gênio considerar separadamente cada uma das fontes exteriores de nossas Ideias ou tomar cada sentido um após o outro; buscar determinar o que impressões simples ou múltiplas, análogas ou dessemelhantes, devem produzir sobre o órgão pensante; enfim, ver como as percepções comparadas e combinadas engendram os juízos e os desejos".

Mas, enquanto admira a iniciativa de Condillac, Cabanis a declara insuficiente e artificial. Condillac e Charles Bonnet (de Genebra) tiveram ao mesmo tempo a ideia de representar o homem como uma estátua animada da qual todos os sentidos se abrem sucessivamente para estudar as impressões e, ao mesmo tempo, as ideias que nascem de cada um deles. Cabanis nos faz sentir o quanto esse processo, se nele vemos algo diferente de um processo de estudo, é em si mesmo falso e superficial: "Nada se parece menos com a realidade, diz ele, do que essas estátuas que supomos serem subitamente dotadas da faculdade de experimentar distintamente as impressões atribuídas a cada sentido em particular". Como médico e filósofo, ele se surpreende com o fato de essas operações poderem se executar "sem que os órgãos se desenvolvam por graus e tenham adquirido essa espécie de instrução progressiva que os capacita a desempenhar suas próprias funções e a associar seus esforços, dirigindo-os para o objetivo comum". $\mathrm{Na}$ realidade, é impossível separar os sentidos uns dos outros e privá-los de toda ação vital: “Nada se assemelha menos à maneira cujas sensações são percebidas, cujas ideias e os desejos se formam realmente, do que essas operações parciais de um sentido que age num isolamento absoluto do sistema e que é mesmo privado de sua influência vital, sem a qual não poderia haver sensação". A ideologia de Condillac era absolutamente estranha a toda fisiologia: o sentido foi separado do órgão e todos os sentidos separados entre si, embora na realidade eles sejam apenas os vários florescimentos de uma única propriedade ligada à vida ela mesma, isto é, a potência do sentir.

Descartes e Malebranche atribuíram uma importância muito maior do que nossos ideólogos às funções corporais. Foram sobretudo as escolas de Locke e de 
Condillac que fizeram da ideologia uma ciência inteiramente separada. Quando Condillac nos fala de uma estátua "animada", ele não nos diz o que se deve entender por animada. Parece que bastaria abrir algumas portas, como num autômato, para fazer entrar de fora impressões e ideias. Mas, para sentir, é preciso viver, e na estátua de Condillac nada vive, nada palpita, nada se move. Rousseau, em seu Pigmaleão ${ }^{3}$, fez viver repentinamente sua estátua, Galatea, e a fez dizer tocando-se a si mesma: "Sou eu". Mas tratava-se de um prodígio, de uma metamorfose operada pelos deuses. A estátua de Condillac não tinha mais o mesmo direito que a de Pigmaleão de dizer: "Sou eu"; ela não tinha sequer o direito de dizer a si mesma "cheiro de rosas"; pois, para ela, seria necessário antes de tudo viver, e ela não vivia mais do que o pato de Vaucanson. Enfim, esse método abstrato que separa os sentidos uns dos outros não é mais conforme à realidade: pois, ainda que pudéssemos conceber um homem sem a visão, sem a audição, sem o olfato, não poderíamos concebê-lo sem o tato e sem uma certa sensibilidade geral que talvez seja o próprio fundo da vida. O olho, o nariz, a orelha gozam de uma maravilhosa sensibilidade táctil: é exatamente isso que explica por que o cego de nascença, quando operado de catarata, reporta ao tato do olho as novas impressões que recebe. Os sons também afetam o toque e podem até abalar diferentes partes do corpo; as impressões degustativas, se não são em si mesmas, como diz Cabanis, impressões tácteis, estão certamente associadas de maneira indiscernível a essas. Mas, além dessa conexão geral do tato com todos os sentidos, existem ainda outras conexões mais particulares. O paladar e o olfato, por exemplo, formam quase que um mesmo e único sentido: o olfato é a sentinela do paladar. Nenhuma sensação é percebida isoladamente: todas elas estão ao menos unidas a uma sensação geral, que é a sensação vital. Poderíamos acreditar, enfim, que

\footnotetext{
${ }^{3} \mathrm{O}$ mito grego de Pigmaleão e Galatea é narrado nas Metamorfoses de Ovídio. O escultor Pigmaleão, cansado de ver defeitos nas mulheres reais com quem convivia, preferiu esculpir uma estátua que correspondesse ao seu ideal de mulher, apaixonando-se em seguida por ela. Apiedando-se de Pigmaleão, a deusa Afrodite acabou por dar vida a Galatea. Esse mito recebeu diversas recriações no século XVIII, sendo uma delas a de Jean-Jacques Rousseau [N.T.]
}

Voluntas, Santa Maria, v.12, n.1, p. 01-31, jan./abril, 2021 
houvesse um momento em que a estátua de Condillac não possuísse nenhum sentimento de exterioridade, crendo-se pura e simplesmente cheiro de rosa ou de jasmim? E supondo-se, como queria Destutt de Tracy, que essa noção de fora viesse tão-somente do movimento impedido ${ }^{4}$, não seria ainda uma abstração arbitrária separar o uso dos sentidos da faculdade do movimento?

Não apenas os sentidos externos são inseparáveis e se modificam mais ou menos entre si; mas, o que é ainda mais importante, eles sofrem a influência dos órgãos internos e da vida vegetativa. Assim, ninguém desconhece as relações do paladar e do olfato com o estado do canal intestinal. Certas doenças do sistema nervoso e mesmo do estômago e do diafragma modificam o sentido da audição. A visão igualmente pode ser alterada por distúrbios intestinais, e o fluxo da circulação em geral pode ativar ou embotar as sensações. Os sentidos não são, pois, independentes do resto do organismo e, em particular, do sistema nervoso. Enfim, e acima de tudo, eles não são independentes do sistema cerebral.

Assim, o erro fundamental de Condillac, segundo Cabanis, é o de ter conhecido e estudado unicamente as sensações externas; é o de ter acreditado que bastaria combinar todas essas sensações adventícias para formar delas pensamentos. Ele não viu uma outra fonte, mais profunda, mais íntima, permanente e contínua, que exerce uma influência invisível, mas invencível, sobre a formação de nossas ideias, ao mesmo tempo em que exerce influência sobre nossos humores e nosso caráter: é a sensibilidade orgânica, aquela que se mistura a todo o corpo, ligando-se às vísceras, às secreções e que constitui, enfim, a própria fonte da vitalidade.

Sem dúvida, não há como esperar que se possa analisar, decompor e classificar essas impressões internas como Condillac o fez para as impressões

\footnotetext{
${ }^{4}$ Cabanis mudou, ou pareceu mudar, sua opinião sobre a exterioridade depois de ler o memorial de Destutt de Tracy no Institut, sobre a Faculdade de pensar. Lá, ele demonstrava (cap. I) que "não é ao sentido do tato que devemos o conhecimento do corpo" (Mémoires de I'Institut National, sciences morales et politiques, t. I, p. 291; termidor, ano VI). Sobre este ponto, Cabanis substituiu, na versão impressa do seu memorial intitulado Histoire physiologique des sensations, § V, a frase contida na versão original do memorial (ver Mémoires de I'Institut, t. I, p. 124). [N.A.]
} 
externas: pois cada sentido exterior tem suas sensações próprias, ao passo que não sabemos quais são as impressões particulares ligadas aos órgãos da nutrição, por exemplo ao fígado, ao baço ou ao estômago; isso se torna ainda mais difícil pelo fato de termos uma percepção muito confusa dessas impressões - exceto nos casos de doença - ou mesmo, na maior parte do tempo, nenhuma percepção. Mas o que nos autoriza a supor que essas impressões exercem na origem uma certa ação sobre os centros cerebrais é que, mesmo num dado estado atual, vemos os órgãos internos, segundo suas várias disposições, exercendo sua influência sobre o órgão cerebral e consequentemente sobre o pensamento; isso é demonstrado pela patologia e até pela observação vulgar. Sabemos que a loucura muito frequentemente sua provém dos distúrbios dos órgãos intestinais. Os distúrbios, e mesmo as revoluções naturais que ocorrem nos órgãos generativos, também têm seus impactos no pensamento e especialmente na imaginação; sabemos da sua influência sobre os sonhos; ocorre o mesmo com a nutrição: os fenômenos do pesadelo são um de seus efeitos mais patentes. Da mesma forma, a ação de narcóticos e bebidas fortes sobre a mente é inquestionável; ora, mas esses agentes só afetam diretamente o estômago e os intestinos. Enfim, é o estado geral da organização que faz nascer o sentimento fundamental da existência e esses estados de bem-estar e desconforto vagos e difusos que constituem o nosso humor, que intervêm no desenvolvimento de nossa inteligência, seja para facilitála, seja para impedir seu curso.

Por conseguinte, a filosofia de Condillac é insuficiente porque só considera a sensibilidade externa, negligenciando completamente os sentidos propriamente ditos e omitindo uma outra parte da sensibilidade, não menos importante e assumida pela outra, a saber, a sensibilidade interna ou vital e todas as impressões e determinações que dela derivam.

Vemos a importância desta primeira modificação introduzida por Cabanis na doutrina condillaquiana. É muito mais grave e profunda do que a de Destutt de Tracy, que, no entanto, também teve um grande valor. Este último havia apontado 
a importância do fenômeno do movimento na formação de nossas percepções. Havia assinalado que, sem o movimento, e sobretudo sem o movimento voluntário, e finalmente sem o movimento impedido, não haveria a noção de mundo exterior. Essa aposta feita ao movimento na percepção externa é um ponto de vista notável, e os psicólogos ingleses contemporâneos, por exemplo Alexander Bain, atribuem com razão um alto valor a ela. Eles só erram em ignorar, junto a muitas outras coisas, que essa visão é própria à psicologia francesa, e em particular a Destutt de Tracy e a Maine de Biran. Esse foi, evidentemente, um progresso notável com relação à filosofia de Condillac. Contudo, essa reforma dizia respeito a um único ponto especial. Ao contrário, a reforma de Cabanis renovava e transformava o condillaquismo sob todos os pontos. Ele cavou mais fundo do que os ideólogos, e mais além do que a sensibilidade externa, liberou a sensibilidade interna, que é a base da externa sendo, no entanto, distinta dela. Locke, Condillac, Hume, enfim, quase todos os filósofos do século XVIII consideraram o homem apenas de fora. Eles haviam ignorado o homem interno, quero dizer, a sua organização interna, como se isso não dissesse respeito à sua vida moral. Mesmo aqueles que tentaram apartar o físico no homem, como Charles Bonnet e Hartley, viram no físico, como o próprio Descartes, apenas um mecanismo autômato, que eles desmontaram artificialmente, como a estátua de Condillac; nenhum deles havia apontado, com a atenção que merece, o fato capital da sensibilidade vital. Para reencontrar a origem dessa visão, seria preciso consultar os médicos e fisiólogos do século XVIII, Stahl, Bordeu, Haller e, entre os filósofos, Diderot e Maupertuis; mas este não é o lugar para se lançar a tal pesquisa. Contentemo-nos em dizer que, segundo o princípio de que uma ideia em filosofia pertence àquele que é o primeiro a ter uma consciência distinta dela e a ver suas consequências, é Cabanis que deve ser considerado como tendo introduzido em psicologia o princípio das sensações internas ou orgânicas; e, mais uma vez aqui, os psicólogos ingleses de hoje que, em sua análise das sensações, partem da sensibilidade interna, ignoram que esta também é uma visão da psicologia francesa. Não apenas, nessa ordem de pesquisa, 
os ingleses não ultrapassam Cabanis, como estão longe de tê-lo igualado em profundidade e precisão.

Se fosse o caso aqui, gostaríamos de mostrar como a psicologia profunda de Maine de Biran se relaciona com essa dupla raiz, por um lado com Destutt de Tracy e, por outro, com Cabanis. É a Destutt de Tracy que Maine de Biran deve seu grande princípio do esforço voluntário, de onde tirou conclusões tão importantes que Tracy não previra; é a Cabanis que Biran deve sua teoria da "vida afetiva", como ele a chama, isto é, dessa sensibilidade surda e difusa, contemporânea da vida, anterior e estrangeira ao eu, e cuja sede está nos órgãos internos. O desenvolvimento simultâneo desses dois pontos de vista o levou a uma nova teoria do homo duplex, que, partindo do condillaquismo e do sensualismo, foi a renovação do espiritualismo na filosofia francesa, sendo verdadeiro que os opostos nascem dos seus contrários, como disse Platão, e como disse Hegel depois dele!

Não apenas Cabanis, ao opor o princípio da sensibilidade interna a Condillac, modificou seriamente o sistema desse filósofo; mas, desse princípio, ele tirou conclusões que chegaram até a reviravolta completa do sistema. É aqui que nos deparamos com o ponto em que a filosofia de Cabanis vai ao encontro da de Schopenhauer.

Uma das consequências mais importantes disso é que a criança, no momento daquilo que chamamos de nascimento, não é uma "tabula rasa". Estamos em presença, aqui, de uma forma inteiramente nova da doutrina do inatismo. Sem dúvida, não se trata de um inatismo absoluto, de certo modo metafísico, mergulhando nas profundezas da substância; trata-se de um inatismo bastante relativo, mas que podemos levar tão longe quanto quisermos. Quando dizemos que todas as nossas ideias vêm da experiência, de que experiência queremos falar e em que momento temos essa experiência? É na hora do nascimento? Será o recém-nascido uma tabula rasa? Não terá ele sentido nada antes de receber a impressão do ambiente externo? Era ele uma estátua até então? Não, sem dúvida; antes daquilo que chamamos de nascimento, isto é, antes de seu 
aparecimento para o meio externo, ele já havia sentido. Mas até onde deveríamos voltar? Em que momento preciso podemos argumentar que o feto, ou o embrião, deixa de ser uma tabula rasa, mas que o era antes? Vemos como a teoria da estátua é incapaz de responder a essas perguntas. Cabanis, por seus hábitos de médico, teria de ser levado a considerar o homem de maneira mais concreta e a enfrentar questões de que Condillac não suspeitava. Ele lançou, assim, as bases para o que pode ser chamado de psicologia intrauterina ${ }^{5}$.

O feto tem sensações externas? Este é o primeiro ponto a ser decidido. Cabanis se inclina a pensar que, mesmo antes do nascimento, ele já deve haver alguma impressão dos corpos externos: o que o prova é o movimento, que é inseparável, diz ele, da noção de resistência: o feto deve sentir, ao menos, o peso e a resistência de seus próprios membros, pois nenhum movimento ocorre sem resistência dos músculos e provavelmente sem alguma sensação correspondente. Também é provável que haja alguma sensação de temperatura, o que pode ser garantido aplicando-se um corpo muito frio sobre o ventre da mãe. Mas, embora possa haver dúvidas sobre a sensibilidade externa do feto, não há nenhuma sobre a sensibilidade interna dos órgãos vitais e, além disso, há uma simpatia com a sensibilidade materna. A sensibilidade se confunde, enfim, para Cabanis com as próprias origens da vida: "Viver é sentir". O sentimento está essencialmente ligado ao movimento, e talvez mesmo, diz ele, esses dois fenômenos sejam basicamente um só: "Sem dúvida, diz ele, as sensações e as impressões dependem de causas situadas fora dos nervos que as recebem, há sempre um instante breve como um raio em que sua causa age sobre os nervos sem que nenhum tipo de movimento ainda ocorra; podemos distinguir, pois, a faculdade de sentir da faculdade de se mover. Não devemos dissimular, contudo, que essa distinção possa muito bem desaparecer em uma análise mais severa, e que assim a sensibilidade talvez se ligue por alguns pontos essenciais às causas e às leis do movimento, fonte geral e

\footnotetext{
${ }^{5}$ Hoje em dia, falamos de psicologia celular (Hæckel); está-se indo muito mais além, mas uma coisa leva à outra, pois não se sabe onde parar. [N.A.]
}

Voluntas, Santa Maria, v.12, n.1, p. 01-31, jan./abril, 2021 
fecunda de todos os fenômenos do universo". Aqui, mais uma vez, devemos assinalar em Cabanis uma das visões apresentadas pelas escolas contemporâneas como uma das mais avançadas em ciência filosófica, a saber, que sentimento e movimento são um mesmo e único fenômeno considerado de dois pontos de vista diferentes.

No estado atual de nossos conhecimentos, essa redução é impossível. No entanto, esses dois fatos, distintos pela análise, são de fato inseparáveis. Toda sensação determina um movimento; toda sensação contínua deve levar a movimentos contínuos que se tornam cada vez mais fáceis de tanto serem repetidos, e produzem tendências a reproduzi-los, isto é, hábitos, apetites e, para dizer a palavra correta, "instintos".

Condillac havia explicado todos os movimentos e todas as ações do homem por meio da experiência refletida. Cabanis, ao contrário, distingue o instinto. Há, sem dúvida, os movimentos combinados, refletidos, calculados, fundados sobre a experiência e cuja origem está nos sentidos externos. Mas há também outros movimentos cuja origem está nos sentidos internos. Ora, como o caráter das sensações internas deve estar acompanhado de uma consciência obscura, confusa, incerta e, muitas vezes, como veremos adiante, estar sem consciência, segue-se que as determinações ligadas às sensações internas são elas próprias "determinações sem consciência"; as primeiras são voluntárias, as últimas são consideradas "instintivas".

Disso advêm dois princípios de ação, um dos quais foi absolutamente ignorado por Condillac, o instinto, e que é anterior ao outro, ou melhor, que é mesmo a base do outro. Sua origem se perde na própria origem da vida. Cabanis oferece numerosos exemplos para mostrar que o feto, antes do nascimento, já contraiu hábitos, instintos, apetites, tais que esses hábitos não podem ser explicados pela experiência, pois muitas vezes são eles que antecipam o que virá depois, e também observamos animais buscando se servir de órgãos que ainda não possuem, trabalhando para filhotes que ainda não têm e que talvez nunca 
venham a ter: enfim, eles antecipam até a experiência externa, visto que o pintinho mordisca o grão à distância sem se enganar, no momento mesmo em que sai de seu ovo. Essa restauração do elemento instintivo na doutrina de Condillac é um fato da maior importância: é uma espécie de retorno ao inatismo, porque não há proporção aqui entre causa e efeito, entre uma sensação vaga e obscura e um movimento apropriado. Poderíamos levar mais longe tal questão, perguntandonos se não haveria aqui uma verdadeira espontaneidade, se a sensação não seria apenas a causa ocasional e excitadora, em vez de ser a causa total do movimento e, finalmente, se o movimento, em vez de ser determinado pela sensação, não seria apenas seguido ou acompanhado por ela; enfim, se esses dois fenômenos não seriam dois sinais correlativos, mas independentes da atividade vital. Essa seria a doutrina que os princípios de Cabanis poderiam autorizar; mas este último, sempre fiel no fundo, mesmo quando a combate, à doutrina de Condillac, persiste em ver na sensibilidade o antecedente necessário do movimento.

Mas o que ele entende por sensibilidade? Vemos aparecer aqui uma doutrina muito cara aos fisiólogos contemporâneos e aos filósofos alemães mais recentes: é a doutrina de uma sensibilidade não sentida, ou, como diríamos hoje, "inconsciente". Muitos filósofos e, sobretudo, muitos fisiólogos, diz Cabanis, só reconhecem sensibilidade onde a consciência das impressões se manifesta nitidamente: essa consciência é, aos seus olhos, o caráter exclusivo e distinto da sensibilidade. "Contudo", acrescenta ele, "nada é mais contrário aos fatos fisiológicos bem apreciados". Em apoio a essa tese, Cabanis cita os seguintes fatos: a possibilidade de ainda excitar os nervos e músculos mesmo após sua separação do centro nervoso, seja por ligadura, seja por amputação, seja pela morte; a ação contínua e incontestável da circulação, da digestão, da absorção sobre nosso humor, nossas ideias e nossas afecções. Alguém poderia perguntar se não estaríamos aqui diante de uma questão de palavras. O que ele está chamando de sensibilidade não seria simplesmente o que outros chamam de excitabilidade, irritabilidade? "Não", responde Cabanis, "e eis a diferença. A irritabilidade é a 
faculdade de contração que parece inerente à fibra muscular ${ }^{6}$. Mas nos movimentos orgânicos coordenados, há mais do que isso". Ora, há vários movimentos desse tipo que são determinados por impressões das quais o indivíduo não tem consciência, e que na maioria das vezes fogem à sua observação; e todavia, como os movimentos voluntários e conscientes, "eles cessam com a vida; eles cessam quando o órgão deixa de ter comunicação com os centros; em suma, eles cessam com a sensibilidade". Assim, o caráter próprio da sensibilidade é o de dar origem, não a reações mecânicas, mas a movimentos "coordenados e apropriados". Ora, é isto que pode acontecer sem consciência. Agora, se pode haver sensibilidade sem consciência no sistema geral ligado ao centro principal, ou seja, ao encéfalo, por que não deveria haver sensibilidade também nos sistemas subordinados ligados aos centros interiores? Por que um animal que consideramos como uma unidade, já que só consideramos o eu central, não seria um conjunto de sistemas coordenados e subordinados, cada um com sua própria sensibilidade? Consequentemente, por sob a sensibilidade geral que anima todo o organismo, podemos supor que exista uma sensibilidade local inferior que anima as diferentes regiões do organismo. Vemos essa doutrina do feudalismo orgânico cada vez mais difundida na fisiologia contemporânea. Quer a identifiquemos com a série de graus do inconsciente de Hartmann, quer com outros autores, admite-se uma hierarquia de subconsciências, um entrelaçamento de pequenos eus envolvidos uns nos outros até o infinito, doutrina que já teve sua fonte em Leibniz e que, bem longe de ser a introdução do materialismo na psicologia, é ao contrário a vingança do espiritualismo contra a fisiologia. Nós a encontramos em termos explícitos em Cabanis, e foi nele que Schopenhauer pôde encontrar uma das origens de seu sistema. Vejamos, com efeito, a analogia, não apenas no pensamento, mas nos

\footnotetext{
${ }^{6}$ Aqui Cabanis confunde irritabilidade com contractilidade, que é uma propriedade particular no sistema muscular. Mas não vemos por que não deveríamos dar o nome de irritabilidade à faculdade, geral ou local, de reagir às impressões externas, e por que não reservaríamos o nome de sensibilidade para a faculdade de gozar e de sofrer com consciência; pois, de outro modo, como chamaríamos a esta última faculdade? [N.A.]
}

Voluntas, Santa Maria, v.12, n.1, p. 01-31, jan./abril, 2021 
termos, que as seguintes passagens apresentam com a doutrina do filósofo alemão. “Devemos considerar o sistema nervoso como suscetível a se dividir em vários sistemas parciais inferiores, todos com seu centro de gravidade... Talvez, como o imaginava Van Helmont, seja formada em cada sistema e em cada sentido uma espécie de eu parcial, relativo às impressões cujo centro é o ponto de encontro... Não podemos formar uma ideia clara e precisa dessas vontades parciais... Estamos, pois, inclinados a considerar cada centro como uma espécie de eu verdadeiro".

Cabanis não se detém ainda nessa suposição de eus parciais, de vontades parciais; ele se eleva até a concepção da causa geral dos fenômenos vitais e a procura em um princípio que abarcaria ao mesmo tempo todos os fenômenos da natureza. Ele supõe haver "alguma analogia entre a sensibilidade animal, o instinto das plantas, as afinidades eletivas e simples atração gravitacional". E em todos esses fenômenos ele vê um fato comum, "a tendência de os corpos irem uns em direção aos outros". Mas qual é a fonte à qual se pode atribuir a origem desta tendência? Cabanis, movido pelas ideias favoritas de seu século e seduzido pelas maravilhas então recentemente reveladas por Alessandro Volta e Luigi Galvani, é levado a acreditar que o agente universal cujos fenômenos do universo seriam a manifestação é a eletricidade. Mas isso ainda é apenas a aparência; é linguagem de físico; o metafísico e o filósofo se elevam mais alto. Este último, pretensamente o apóstolo do materialismo, pede ao espírito, o que há de mais alto na natureza, o segredo do verdadeiro fundamento das coisas: "Seria permitido", questiona Cabanis, "levar as consequências mais adiante? As afinidades vegetais, as atrações químicas, essa tendência própria a toda matéria de ir em direção ao centro, todos esses atos diversos ocorreriam por uma espécie de instinto universal inerente a todas as partes da matéria?... E esse instinto, desenvolvendo-se cada vez mais, não poderia se elevar às maravilhas mais admiradas da inteligência e do sentimento? Seria pela sensibilidade que explicaríamos as outras atrações, ou pela gravidade é que explicaríamos a sensibilidade e as tendências intermediárias? É isso que, no estado atual do conhecimento, é impossível prever. Mas se um dia estivermos na posição 
de poder reduzir o sistema inteiro a uma causa comum, é verossímil que sejamos conduzidos até aí pelo estudo dos resultados mais completos, mais perfeitos e mais nítidos do que pelos mais limitados e mais obscuros: pois aqui não é o lugar para ir do mais simples ao mais complexo. Aliás, não seria natural pensar que as operações cujo caráter e os efeitos podemos observar em nós mesmos seriam mais aptas a lançar luz sobre as que se realizam longe de nós do que estas últimas para nos fazer analisar melhor o que estamos fazendo e sentindo a cada momento?".

Esta página capital contém em germe toda a filosofia de Schopenhauer, com a única diferença que Cabanis chama de sensibilidade o que ele chama de vontade: e mesmo este termo não falta, já que vimos acima que ele falava de "vontades parciais" ligadas aos centros inferiores; e como ele mesmo diz em outro lugar "que o eu reside acima de tudo na vontade", ele sem dúvida não teria recusado chamar de vontade o princípio que anima o eu universal residente na natureza, como ele chama de vontade o princípio de ação que anima os eus parciais residente nos órgãos subordinados.

Quando refletimos sobre essa doutrina com a qual se encerra o livro sobre as Relações entre o físico e o moral, ficamos menos surpresos com a alegada contradição que pensamos ter visto entre esta obra e a Carta a Fauriel sobre as causas primárias; assim como em seus Relatórios, Cabanis acabou por se elevar acima do materialismo, também na carta a Fauriel ele se eleva acima do ateísmo de Lalande e de Naigeon; ele toma decididamente o partido da finalidade na natureza e, também por isso, sua filosofia pode ter tido alguma influência sobre a de Schopenhauer.

II.

Bichat pertence à história da ciência sobretudo como fundador da anatomia geral: é o título que Ihe dá Claude Bernard. Foi ele quem teve a ideia de penetrar, no estudo do corpo vivo, além desses compostos aparentes que chamamos de 
órgãos, para buscar as propriedades do próprio estofo de que esses órgãos são formados e que leva o nome de membranas ou tecidos. "O que caracteriza a obra científica de Bichat", diz Claude Bernard, "é ter estudado cuidadosamente as propriedades de cada um desses tecidos e ter localizado neles um fenômeno vital elementar. Cada tecido elementar representava uma função particular. Todas as propriedades vitais foram trazidas de volta aos tecidos, e isso foi uma revolução análoga à que Lavoisier acabara de fazer alguns anos antes no estudo dos corpos inorgânicos".

Não é desse ponto de vista que devemos considerar Bichat. O que nos interessa e que Ihe confere um lugar de destaque na história da filosofia é sua célebre obra sobre $A$ vida e a morte ${ }^{7}$, tão cheia de visões originais e profundas e escrita com método e clareza superiores. A necessidade de precisão que sua mente sentia no mais alto grau o leva, às vezes, a distinções muito marcadas, que não deixam espaço suficiente para fenômenos intermediários. Mas em questões tão delicadas e tão complexas, é proveitoso deixarmo-nos ser conduzidos como que pela mão, seguindo um gênio tão luminoso e tão metódico, de tal modo que nos seria reprovado apontar como excessiva uma qualidade que é o traço característico do espírito francês.

Conhecemos a famosa definição que Bichat deu sobre a vida: ela é, diz ele, "o conjunto das funções que resistem à morte". Esta definição parece, à primeira vista, uma tautologia, pois não parece dizer outra coisa senão isto: que a vida é o contrário da morte, enquanto a morte por sua vez só nos é conhecida como o contrário da vida. Mas seria um engano reduzir o pensamento de Bichat a termos tão frívolos. Claude Bernard deu-Ihe um sentido muito mais sério, que era o verdadeiro, ao dizer que tal frase poderia ser traduzida nestes termos: "A vida é o conjunto de propriedades vitais que resistem às propriedades físicas". O que Bichat queria expressar era o antagonismo entre a vida e o meio inorgânico. Tudo o que

\footnotetext{
${ }^{7}$ A obra Recherches physiologiques sur la vie et la mort [Investigações fisiológicas sobre a vida e a morte] foi publicada por Bichat em 1800. [N.T.]
}

Voluntas, Santa Maria, v.12, n.1, p. 01-31, jan./abril, 2021 
rodeia os corpos vivos, dizia ele, tende a destruí-los, e eles sucumbiriam necessariamente se não tivessem em si "um princípio de reação"; este princípio é a vida. Há uma constante alternância entre ação e reação do corpo circundante e do corpo vivo, e as proporções dessa alternância variam com a idade. Na infância, é o princípio da vida que superabunda; na fase adulta, a equação se estabelece; a faculdade de reação se enfraquece sem cessar na velhice; quando, enfim, ela cessa totalmente, a vida cessa com ela, e é isso o que chamamos de morte. "Diz-se que Prometeu, tendo formado algumas estátuas de homens, roubou o fogo do céu para animá-los. Este fogo é o emblema das propriedades vitais: enquanto queima, a vida se sustenta; ela se aniquila quando ele se extingue".

Vemos que Bichat defendia essa ordem de ideias que chamamos de vitalismo. Ele não definiu, sem dúvida, o princípio da vida; ele não fez dele, como Barthez ou como Stahl, um princípio imaterial; em vez disso, ele parece tê-lo ligado aos tecidos orgânicos como uma propriedade ou um atributo; ele aprovou, enfim, aquele tipo de vitalismo que reinou por muito tempo na Escola de Paris sob o nome de "organicismo". Contudo, ele estabeleceu, como vimos, uma oposição radical entre as propriedades vitais e as propriedades físicas; ele parecia acreditar em forças especiais suspendendo a ação das forças inorgânicas. Claude Bernard, que oscilava com frequência quanto a essas questões de princípio, combateu o antagonismo de Bichat. A vida, dizia, é uma combustão; e a combustão é, no fundo, apenas um fenômeno químico. As propriedades vitais, longe de se equilibrar com as propriedades físicas e químicas e de suspender sua ação, são ao contrário tanto mais ativas quanto estas mesmas o são. Porém, quando Claude Bernard, por sua vez, define a vida como "uma criação", não está apontando para um traço novo e original que faltaria à matéria bruta? O símbolo da vida, diz ele, é "uma tocha que se reacende a si mesma". Mas esta tocha mesma, não é nada? E onde encontrar algo de semelhante na matéria inerte? Não existe nela algo que resiste à morte e que é o quid proprium da vida, segundo a própria expressão de Claude Bernard? De qualquer forma, já dissemos o suficiente para deixar claro que a definição de 
Bichat está longe de ser uma tautologia e que ela toca os pontos mais profundos da filosofia fisiológica.

Além disso, não é por sua teoria geral da natureza da vida que Bichat deixou a sua marca, pois neste ponto apenas seguiu os passos de Bordeu e Barthez. É sobretudo por sua teoria das duas vidas: a vida orgânica e a vida animal; esta última comum ao vegetal e ao animal, aquela própria apenas ao animal; uma totalmente interna, a outra externa; uma limitada às funções de nutrição e reprodução, a outra residindo principalmente nas funções de relação. O vegetal, diz ele, é como "o esboço e a tela" do animal. Para transformá-lo em animal, basta revesti-lo de aparelhos exteriores capazes de estabelecer relações com o lado de fora. Ao adquirir uma vida superior, o animal não renuncia à vida do vegetal; ele reúne em si as duas vidas. Donde um dualismo que Maine de Biran frequentemente invocou, propondo-se ir além dele, distinguindo também duas vidas na psicologia: a vida animal e a vida humana.

As duas vidas, segundo Bichat, dividem-se cada uma em duas ordens de funções. Na vida animal, por exemplo, há aquelas que vão do exterior ao cérebro, e aquelas que vão do cérebro ao exterior, isto é, aos órgãos da locomoção e da voz. No primeiro caso, o animal é passivo; no segundo, ele é ativo. Uma proporção exata regula essas duas ordens de funções: a vivacidade do sentimento produz a vivacidade do movimento; a lentidão e o entorpecimento das sensações têm por consequência a suspensão do movimento: é o que vemos no sono e nos animais em hibernação. O mesmo ocorre com a vida orgânica; há também dois tipos de funções e dois movimentos em sentido inverso: "um compõe, o outro decompõe", assimilação e desassimilação. Por um lado, o animal agrega as matérias externas necessárias à conservação de seu ser; por outro, devolve para fora as substâncias que se tornaram heterogêneas à sua organização. Entre as funções assimilativas, as principais são a nutrição e a respiração; as funções de desassimilação são: a absorção, a expiração e a secreção. A circulação serve de passagem entre as duas: “o sistema sanguíneo é um sistema médio, centro da vida orgânica, assim como o 
cérebro é o centro da vida animal". Mas não há aqui, entre as duas ordens de funções, a mesma proporção que há entre as duas funções da vida animal; o enfraquecimento nas funções nutritivas não tem por consequência parar o progresso da função excretiva: ao contrário, o animal morre se não consegue reparar suas perdas.

Bichat compara, em seguida, as duas vidas, tanto em relação aos órgãos, como em relação às funções. Quanto aos órgãos, o caráter essencial da vida animal é a simetria, e o da vida orgânica, a irregularidade. Vejamos, com efeito; os órgãos dos sentidos são duplos: dois olhos, duas orelhas, duas narinas; o próprio órgão do paladar é dividido por uma linha mediana que o separa em duas partes semelhantes ou iguais de cada lado; ocorre o mesmo com o tato. O cérebro é igualmente duplo, ele é dividido em dois hemisférios que se suprem mutuamente. As partes pares são semelhantes em ambos os lados; as partes ímpares são simetricamente divididas por uma linha mediana que às vezes é até visível, como no corpo caloso; o mesmo vale para os nervos motores, para os músculos voluntários e para os nervos da voz. Ao contrário, na vida orgânica os órgãos e o sistema nervoso apresentam o caráter da irregularidade: por exemplo, o estômago, os intestinos, o baço, o coração, os grandes vasos e os órgãos de expiração e de absorção. Existem exceções apenas para os órgãos respiratórios, pois há dois pulmões e dois aparelhos respiratórios simétricos; no entanto, ainda há grandes diferenças entre os dois pulmões em seu diâmetro e em sua direção. Um deles tem três lóbulos, o outro apenas dois. Do mesmo modo, os dois ramos da artéria pulmonar não são semelhantes em sua direção ou diâmetro. Assim, a vida animal é dupla: há uma vida direita e uma vida esquerda; elas podem se suprir reciprocamente, que é o que acontece na hemiplegia. Ao contrário, a vida orgânica forma um sistema único, onde as funções não podem ser interrompidas de um lado sem cessar do outro; se os órgãos da esquerda cessam suas funções, os da direita são interrompidos; há exceções apenas para os pulmões e os rins, que podem complementar-se. Da lei anterior resulta a consequência de que há muito 
mais desvios de conformação nos órgãos da vida orgânica do que nos da vida animal; esses desvios podem chegar a uma perturbação total do sistema.

Se passarmos dos órgãos às funções, descobriremos que o caráter das funções animais é a harmonia, e o das funções orgânicas é a discordância. A harmonia vem da dualidade e da semelhança dos órgãos; quanto mais semelhantes os órgãos, mais harmoniosas são as funções: quando os dois olhos têm conformações diferentes, a visão está alterada; se um é forte e o outro fraco, um deles deixa de enxergar: daí o estrabismo. O mesmo se aplica ao ouvido; a falta de precisão vem do fato de que um dos ouvidos não transmite a mesma sensação. É isso que Buffon já havia notado. Bichat aplica a mesma observação aos outros sentidos: a ação desigual das duas narinas produz o efeito de odores confusos; é o que ocorre com a coriza, quando atinge apenas uma narina. É provável que o mesmo ocorra com o paladar, se a língua estiver mais obtusa de um lado do que do outro. Um cego que tiver uma mão imóvel e a outra bem organizada dificilmente terá, ao que parece, noções distintas de tamanho, localização e forma: na verdade, se uma das duas mãos lhe der a sensação de um corpo esférico, e a outra de um corpo irregular, essas duas sensações serão reduzidas a uma sensação confusa. A voz está sujeita à mesma lei. A voz falsa, que pode soar assim a um ouvido justo, deve-se à falta de harmonia entre as duas partes da laringe.

O mesmo princípio vale, segundo Bichat, para os sentidos internos. Se os dois hemisférios do cérebro não são perfeitamente iguais, deve haver confusão nas ideias; são, na verdade, duas mentes diferentes que pensam ao mesmo tempo e se confundem numa só. Se a memória nos lembra uma imagem em um dos dois hemisférios e o outro nos apresenta uma outra, pode a lembrança ser precisa? A perfeição da função depende, pois, da semelhança dos órgãos e de sua identidade de ação. Assim, o que chamamos de correção do intelecto não seria mais do que a harmonia de ação entre os dois cérebros: "Quantas nuances haveria nas operações do entendimento? Essas nuances não corresponderiam a tantas variedades na relação de força entre as duas metades do cérebro? Se pudéssemos vesguear esse 
órgão como os olhos e usar apenas um lado do cérebro, seríamos mestres na correção de nossas operações intelectuais; mas tal faculdade não existe". É pela mesma hipótese que Bichat explica esse fato, que ele parece considerar como exato, a saber, o de que um golpe em uma das regiões laterais da cabeça restabelece o equilíbrio das funções destruídas por um outro golpe na região oposta da cabeça.

Há, porém, uma objeção à teoria precedente: é a superioridade de ação nas partes do lado direito sobre as do lado esquerdo do corpo. Mas é preciso distinguir entre a força e a agilidade: a primeira vem da organização; a segunda do exercício e do hábito. Ora, é somente pela agilidade que a direita prevalece sobre a esquerda. Vemos que Bichat explica pelo hábito essa superioridade singular da direita sobre a esquerda. Ele parece acreditar que houve uma convenção. Convimos, diz ele, em escrever da esquerda para a direita: devemos ter adquirido, por isso, o hábito de ler na mesma direção e, portanto, também o hábito de considerar todos os objetos da mesma maneira. A mesma regra se aplica a todos os movimentos. Como combateríamos juntos, como caminharíamos juntos para o combate, como dançaríamos em compasso e harmonia, se uma convenção geral não tivesse estabelecido uma certa ordem de movimento? Essas considerações são engenhosas, mas não explicam como pode a mesma ordem de movimentos ser acordada entre todos os povos. Deve haver aí, portanto, algo de natural.

Se a harmonia é o caráter da vida animal, a discordância é o caráter da vida orgânica. Nessa ordem de fenômenos, a desigualdade de ação das duas partes não altera a função: elas se acumulam e não se confundem. Se um pulmão respira melhor do que o outro, as duas ações combinadas acabam por desempenhar a função: não estamos falando, é claro, de casos de doença, mas de uma simples desigualdade normal: estabelece-se entre as duas ações uma resultante, que é a mesma que se alguém tirasse de uma das partes o que ela tem a mais para dar à outra. Isso ocorre porque há aqui apenas uma questão de quantidade, enquanto nas funções animais há uma questão de qualidade. Bichat também assinala outras 
diferenças, porém mais contestáveis, entre a vida orgânica e a vida animal. Por exemplo, ele sustenta que as funções orgânicas são contínuas e as funções animais intermitentes. Ele cita como exemplos, de um lado, a circulação, a respiração, a absorção, a secreção; de outro, o sono. Mas não podemos opor, de um lado, a digestão, de outro, as funções do cérebro, e mesmo os sentidos (do tato, por exemplo), da função motora? Bichat distingue, com efeito, entre a remitência e a intermitência: uma diz respeito apenas à intensidade da função, a outra à própria função; mas, na digestão, há mais do que remitência, há realmente interrupção e retomada de função e, consequentemente, intermitência: reciprocamente, podemos afirmar que as faculdades sensoriais e motoras nunca são completamente interrompidas. Há, portanto, aqui um certo excesso na separação das duas vidas.

Outra lei assinalada por Bichat é a de que o hábito exerce seu domínio sobre as funções animais, enquanto sua influência é quase nula sobre as funções orgânicas. Bichat foi o primeiro a enunciar essa lei, geralmente atribuída a Maine de Biran": "O hábito embota o sentimento e aperfeiçoa o juízo"; a lei que Hamilton resumiu nestes termos: "A percepção existe na proporção inversa da sensação". Neste capítulo sobre o hábito, Bichat faz prova de uma grande sutileza psicológica e fornece dados interessantes à análise dos fenômenos internos. Por exemplo, ele nota que o prazer e a dor nascem sobretudo da comparação de cada estado com o estado precedente: quanto mais diferença houver entre dois estados consecutivos, mais vivo será o sentimento. Segue-se que, quanto mais as sensações se repetem enquanto se prolongam, menos elas nos impressionam: "É, pois, da natureza do prazer e da dor destruir-se e cessar de ser". Deveríamos concluir que a constância é apenas um sonho, e que a felicidade está na inconstância? Bichat não tem certeza de como responder à objeção e diz

\footnotetext{
${ }^{8}$ A obra de Bichat é de 1800. O memorial de Maine de Biran sobre o hábito é de 1803; ele foi premiado em 1802. O tema tinha sido proposto pelo Institut National para um concurso em 15 Vendemário Ano VIII, ou seja, em 1799. [N.A.]
}

Voluntas, Santa Maria, v.12, n.1, p. 01-31, jan./abril, 2021 
vagamente: “Guardemo-nos de empregar os princípios da física para inverter os da moral". Esta é uma resposta insuficiente, pois parece que a mesma lei deve reger o sentimento tanto quanto a sensação, e seria então apenas pelo dever que o homem seria mantido na constância; a natureza se oporia a isso. Mas Bichat não percebeu que, se o hábito embota certos prazeres, ele também provoca outros que são aqueles do próprio hábito. René de Chateaubriand, depois de ter buscado a felicidade por todos os meios, acaba por dizer que talvez ela esteja apenas no hábito. Assim, o princípio que dissolve nossos prazeres traz consigo seu remédio.

Uma última diferença, ainda mais profunda do que as anteriores, separa as duas vidas: esta se deve ao que se chama a moral ou a alma. Ora, na alma há duas partes: a parte intelectual e a parte passional. Segundo Bichat, a parte intelectual se relaciona com a vida animal e a parte passional com a vida orgânica. Eis a teoria capital de Bichat e, acima de tudo, é este o elo pelo qual sua doutrina se relaciona com a de Schopenhauer.

Sobre o primeiro ponto, nenhuma contestação é possível: não há dúvida de que a inteligência tem seu substratum no sistema nervoso, isto é, no que Bichat chama de vida animal. Mas é o segundo ponto que merece atenção especial. As paixões, segundo Bichat, têm sua sede, não no sistema nervoso cerebral, mas no sistema visceral, intestinal. Assim também Platão situou nos intestinos o que chamou de terceira parte da alma, ou seja, a alma apetitiva, fonte dos desejos e da

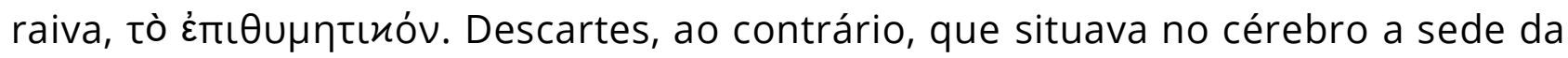
alma, unia no mesmo órgão as paixões e os pensamentos ${ }^{9}$. Bichat retorna ao pensamento de Platão, e situa nas vísceras a origem das paixões; o cérebro é afetado apenas simpaticamente. É surpreendente, sem dúvida, diz ele, que as paixões que ocupam um lugar tão grande em nossa vida intelectual e moral, "não tenham nem seu término nem sua origem" nos órgãos superiores do corpo humano, mas naqueles aos quais são atribuídas funções internas. E, no entanto, é

\footnotetext{
${ }^{9}$ Esta é também a teoria de Bossuet: “Dessa agitação do cérebro e dos pensamentos que a acompanham, nascem as paixões" (De la connaissance de Dieu et de soi-même, cap. III, XI.). [N.A.]
} 
isso que mostram os fatos. O estado das vísceras modifica profundamente o modo das paixões; e, reciprocamente, as paixões, em seus efeitos orgânicos, afetam particularmente as vísceras. De um lado, notamos que o indivíduo cujo aparelho pulmonar é muito pronunciado e cujo sistema circulatório goza de muita energia, em suma, no homem de temperamento sanguinário, tem nas paixões uma impetuosidade que o leva à cólera; o temperamento bilioso predispõe à inveja e à raiva; o temperamento linfático, à preguiça e à lentidão. Da mesma forma, no estado de doença, as afecções do fígado, do estômago, do baço, dos intestinos e do coração determinam uma série de paixões diversas.

As mesmas consequências valem para os efeitos das paixões, que sempre produzem certas mudanças na vida orgânica. A cólera acelera a circulação; a alegria também, embora com mais moderação. O medo age em sentido inverso. Essas afecções podem produzir síncopes que levam à morte ou que deixam lesões orgânicas; a respiração também é alterada: opressões, asfixias, soluços, palavras solavancadas; o mesmo vale também para a digestão: vômitos espasmódicos, interrupção das funções; as secreções estão sujeitas à mesma lei: o medo dá origem à icterícia. As funções de assimilação não são menos perturbadas pelas paixões: a felicidade alimenta; o sofrimento devora. Essas locuções consagradas, estar seco, estar roído de remorso, estar consumido pela tristeza, não indicam o quanto as paixões modificam o sistema nutritivo? A expressão das paixões é mais uma prova da mesma lei: se quisermos indicar nossos pensamentos, a mão vai involuntariamente até a cabeça; quando queremos expressar amor, alegria, tristeza, raiva, é para a região do coração que ela é dirigida. Dizemos uma cabeça forte e um coração sensível; dizemos que a fúria circula nas veias, que a alegria faz estremecer as entranhas, que o ciúme destila seu veneno no coração. As paixões violentas imprimem no leite da ama um caráter nocivo que pode causar doenças na criança.

Entretanto, não podemos negar a ação das paixões sobre os órgãos da vida animal; mas ela só se exerce por simpatia e por intermédio do coração. O coração 
age sobre o cérebro, que dá origem a espasmos e a movimentos involuntários. Neste caso, o cérebro é unicamente passivo, ao passo que é ativo nos movimentos voluntários. Mas o cérebro logo retoma seu império e substitui os movimentos espasmódicos pelos movimentos habituais. Um homem recebe uma carta que o comove: sua testa se enruga, ele empalidece, suas feições se animam; são fenômenos simpáticos nascidos de certas perturbações viscerais, determinadas por essa paixão. Ele retoma a posse de si, seu exterior retorna ao estado habitual; é o movimento voluntário que vence o simpático, é o cérebro que reage contra as vísceras.

Voltemos agora a Schopenhauer e às suas relações com Bichat. Ele mesmo resume sua própria doutrina nesta proposição fundamental: "Aquilo que subjetivamente e do ponto de vista da consciência é intelecto, manifesta-se objetivamente como cérebro; aquilo que subjetivamente e do ponto de vista da consciência é vontade, manifesta-se externamente como o organismo inteiro"10 ${ }^{10}$. É ele mesmo quem diz que esta doutrina não é outra senão a de Bichat. Estas duas teorias apoiam-se mutuamente: é o mesmo pensamento expresso, de um lado, do ponto de vista fisiológico e, de outro, do ponto de vista filosófico; são "o comentário" um do outro. O que Bichat chama de oposição da vida animal e da vida orgânica é, diz Schopenhauer, o que eu chamo de oposição do intelecto e da vontade. É verdade que o próprio Bichat relaciona a vontade com a vida animal, mas é preciso considerar as coisas e não as palavras. Bichat toma a palavra vontade no sentido habitual de livre arbítrio, de árbitro consciente e, neste sentido, com efeito, a vontade depende do cérebro; ainda não se deve ver aqui uma verdadeira vontade, mas apenas a comparação e a ponderação dos motivos; mas o que eu entendo por vontade, prossegue Schopenhauer, é precisamente o que Bichat chama de vida orgânica. As oposições são as mesmas de uma parte e de outra, ainda que um, o anatomista, parta do ponto de vista objetivo; e o outro, o filósofo, do ponto de vista

\footnotetext{
${ }^{10}$ Schopenhauer, Die Welt als Wille..., tomo II (Ergänzungen), cap. 20. [N.A.]
} 
subjetivo: "E é uma verdadeira alegria ver que nós dois, como duas vozes em dueto, caminhamos em harmonia, fazendo soar palavras diferentes". Schopenhauer acrescenta: "Leia-o, quem quiser me compreender; e quem quiser compreendê-lo melhor do que ele a si mesmo, leia-me também" ${ }^{11}$. O que ele acha mais interessante em Bichat, aliás, é a teoria que acabamos de resumir e da qual ele mesmo resume as principais características: a saber, que a vida intelectual se relaciona com a vida animal e, ao contrário, a vida passional à vida orgânica. Enfim, a passagem capital que Schopenhauer cita como sendo a expressão de sua própria filosofia, e que por essa razão guardamos até aqui, é aquela em que Bichat encontra na vida orgânica o fundamento do "caráter" e o representa por isso mesmo como imutável e inalterável. Ora, o caráter é precisamente o que Schopenhauer chama de vontade. É esse fundo absoluto do homem que escapa a toda ação do hábito e do exercício, pois o hábito age sobre a vida animal e não sobre vida orgânica. Eis a passagem de Bichat: "O caráter é, se assim posso me exprimir, a fisionomia das paixões; o temperamento é o das funções internas; ora, sendo ambos sempre os mesmos, é evidente que o temperamento e o caráter devem ser subtraídos ao domínio da educação. Querer desnaturalizar o caráter, suavizar ou exaltar as paixões, é um empreendimento análogo ao de um médico que tenta diminuir em alguns graus e por toda a vida a força de contração do coração, ou precipitar ou desacelerar o movimento natural... Diríamos que a circulação e a respiração não estão sob o domínio da vontade. Façamos a mesma observação àqueles que acreditam que se modifica o caráter e, por isso mesmo, as paixões, já que estas são o produto da ação de todos os órgãos internos"12.

Após ter elevado assim tão alto a doutrina de Bichat, Schopenhauer refuta as objeções que muito mais tarde Flourens levantou contra ela, em seu livro De la

\footnotetext{
11 «Lese, wer mich verstehen will, ihn : und wer ihn gründlicher verstehen vill als er sich verstand, lese mich. » [N.A.]

${ }^{12}$ Após citar esta última passagem, Schopenhauer acrescenta: "Que o leitor familiarizado com minha filosofia possa julgar o tamanho de minha alegria quando as opiniões adquiridas em um campo de estudo totalmente diverso do meu por este homem extraordinário, e levado muito cedo do mundo, trouxeram uma tal prova ao apoio das minhas". [N.A.]
} 
vie et de l'intelligence [Da vida e da inteligência]: "Tudo isso", diz Flourens, "é completamente falso. - So? - Sic decrevit Florentius magnus!". Flourens não dá razões, mas cita autoridades: Descartes e Gall. Descartes, segundo Flourens, é "o filósofo por excelência". Sem dúvida, ele foi um grande homem, um iniciador ${ }^{13}$. Mas declarar-se cartesiano no século XIX é como dizer-se ptolomaico em astronomia, stahliano em química! Flourens afirma, segundo Descartes, que as "vontades são pensamentos". Mas que cada um retorne a si para ver que a vontade e o pensamento são tão diferentes quanto o branco e o preto. De acordo com o oráculo do sr. Flourens, as paixões podem afetar o coração, mas elas têm sua sede no cérebro: assim, elas agem num lugar, mas habitam noutro. As coisas corporais têm o hábito de agir apenas onde estão; mas com uma alma imaterial a questão é bem diferente! Flourens distingue entre o "lugar" das paixões e sua "sede". O que isso pode querer dizer? O erro de Flourens e de "seu Descartes" está em confundir os motivos da vontade que são representações e que repousam no intelecto, isto é, no cérebro, com a própria vontade em si mesma, que nada mais é do que as paixões. Flourens elogia, então, Gall por ter retomado a tradição de Descartes e por ter reconduzido "o moral ao intelectual". Toda a minha filosofia, diz Schopenhauer, é a refutação desse erro: "Sem dúvida", diz ele, para encerrar, “Flourens é um homem de grande mérito e que prestou sobretudo serviços na via experimental. Mas as verdades mais importantes não são aquelas encontradas pela experiência, mas pela reflexão pela penetração. Assim, Bichat, por meio de suas reflexões e de seu olhar profundo, descobriu uma dessas verdades inacessíveis a todas as experiências do Sr. Flourens, para a realização das quais este martirizou até a morte centenas de animais".

O que quer que dela tenha dito Schopenhauer, a doutrina de Bichat sobre a sede das paixões não parece ter sido confirmada pela fisiologia moderna. Não é apenas Flourens, mas também o grande fisiologista alemão J. Müller quem a

\footnotetext{
${ }^{13}$ Ein Bahabrecher, alguém que abre a via, que quebra os obstáculos à sua frente. Schopenhauer gosta dessa expressão, que já havia aplicado a Cabanis. [N.A.]
} 
contradiz: "Nenhuma paixão, diz ele, age diretamente sobre as vísceras; em seres humanos saudáveis, seus efeitos se propagam irradiando-se do cérebro para a medula espinhal e desta para o sistema nervoso, tanto para a vida animal quanto para a vida orgânica. As pessoas dotadas de uma complexão hepática são as únicas em quem uma paixão violenta causa icterícia ou hepatite. Em suma, os efeitos das paixões não fornecem nenhuma prova para apoiar a hipótese de que as paixões têm sua sede fora do cérebro". Citemos casos em que condições puramente orgânicas, como a supressão de uma secreção, determinam o delírio e a loucura; mas essa prova vai além, pois o delírio opera sobre as ideias tanto quanto sobre os sentimentos; dever-se-ia, portanto, concluir disso que tanto a inteligência quanto as paixões têm sua sede nas vísceras. Ademais, quantas vezes tais afecções não se produzem sem culminar em loucura? Se elas têm essa consequência, não é nas vezes em que o cérebro está predisposto às afecções mentais e quando uma perturbação orgânica se espalha gradualmente por simpatia até o centro nervoso? Além disso, a recíproca é verdadeira: quer dizer, muitas vezes acontece que, sem qualquer perturbação orgânica, as paixões são alteradas e modificadas pelo mero estado do cérebro. Sem dúvida, Flourens está errado em elogiar Gall por ter "reconduzido o moral ao intelectual", e Schopenhauer está certo quando distingue a inteligência da vontade; mas esta distinção não exige ou não implica duas sedes diferentes; não é de modo algum necessário situar a fonte da vontade na vida vegetativa e limitar a esfera da inteligência à vida animal. A vida animal é apenas o desenvolvimento da vida orgânica; mas ela compreende tanto a vontade quanto o intelecto; o que há de inconsciente em nós pode ter sua origem mais abaixo, isto é, na vida visceral e vegetativa; mas isso é tão verdadeiro para o que chamamos de inteligência quanto para o que chamamos de vontade.

Pouco importa aqui a verdade intrínseca da doutrina; o único ponto que queremos destacar é a origem francesa da filosofia de Schopenhauer. Essa filosofia, em sua parte objetiva, pode ser reduzida a duas proposições. A primeira é que as diferentes forças da natureza: gravidade, coesão, afinidade, instinto, são, em 
essência, idênticas ao que chamamos de vontade. Ora, encontramos essa proposição fundamental em Cabanis. A segunda é que a vontade está profundamente separada da inteligência e é anterior à inteligência; a vontade é a coisa em si, a substância que aparece para si subjetivamente sob a forma da inteligência. Ora, essa segunda doutrina o próprio Schopenhauer a encontra na distinção das duas vidas, vida orgânica e vida animal, que é a base do livro de Bichat: é a tradução fisiológica de seu sistema. Esse sistema, ao menos em sua parte objetiva, tem, portanto, sua dupla razão na fisiologia francesa. Qualquer que seja o valor dessas ideias, é daqui que elas vieram; é a nossos próprios filósofos que devem ser feitas as homenagens: isso é muitas vezes esquecido pelos admiradores intempestivos de tudo o que vem da Alemanha. Exaltamos Schopenhauer; esquecemos Cabanis e Bichat. Ele mesmo foi mais justo do que nós.

Se fosse aqui o lugar para isso, poderíamos mostrar que, no entusiasmo provocado entre nós pela psicologia inglesa contemporânea, há a mesma ingratidão para com nossos próprios pensadores. Quem quiser estudar com atenção a escola ideológica e fisiológica francesa do início deste século, Destutt de Tracy, Gérando, Maine de Biran, Ampère, e novamente Cabanis e Bichat, ou mesmo Cardaillac e Garnier, encontrará, como vimos, muitas proposições que hoje nos chegam da Inglaterra. Nossos historiadores da psicologia inglesa e da psicologia alemã deverão descobrir um dia que existiu uma psicologia francesa. Será pedir muito a eles, depois de viajarem pelo mundo, que se interessem um pouco por seu próprio país.

\section{REFERÊNCIAS}

BICHAT, X. F. Marie. Recherches physiologiques sur la vie et la mort. Paris, Ed: Gabon Libraere, 1799.

BOSSUET, Jacques-Benigne. De la connaissance de Dieu et de soi-même, cap. III, XI, 1872

CONDILLAC: E. B,. Tratado das sensações. 1754. Trad: Denise Bottmann, Campinas: Ed. Unicamp, 1993. 
Memórias do Instituto Nacional de Ciências e Artes, Instituto Nacional de Ciências e Artes da França para o ano VI da República, p. 291

Memórias do Instituto Nacional de Ciências e Artes, Instituto Nacional de Ciências e Artes da França para o ano VI da República, p. 124.

Ovídio. Metamorfoses. Itália. Diversas Editoras, 8 d. C.

SCHOPENHAUER, Die Welt als Wille..., tomo II (Ergänzungen), cap. 20, 1819.

\section{Contribuição de autoria}

\section{1 - Caio Souto}

Professor Efetivo de Filosofia pelo IFAM

Cursa Estágio de Pós-Doutorado em Filosofia pela PUC-PR

Doutor e Mestre em Filosofia pela UFSCar

Licenciado em Filosofia pela UNIFRAN

Advogado, Bacharel em Direito pela PUC-SP

https://orcid.org/0000-0001-5736-2262•caiosouto@gmail.com

Contribuição: Escrita - Primeira redação

\section{2 - lasmim Martins}

Professora Convidada de Filosofia pela PUC-RJ

Curso Estágio de Pós-doutorado em Filosofia pela UFRJ

Doutora em Filosofia pela PUC-RJ, Mestre em Filosofia pela UFRRJ

https://orcid.org/0000-0001-5277-5041•iasmim.martins98@gmail.com

Contribuição: Escrita - Primeira redação

\section{Como citar este artigo}

JANET, Paul. Schopenhauer e a fisiologia francesa: (Cabanis e Bichat), de Paul Janet. Trad. Caio Souto e Iasmim Martins. Voluntas Revista Internacional de Filosofia, Santa Maria, v. 12, e15, 2021. DOI 10.5902/2179378664887. Disponível em: https://doi.org/10.5902/2179378664887. Acesso em: dia mês abreviado. ano. 